\title{
Worldwide Efficacy of Bismuth Subsalicylate in the Treatment of Travelers' Diarrhea
}

Robert Steffen
From the Division of Epidemiology and Prevention of
Communicable Diseases, Institute of Social and Preventive
Medicine, University of Zurich, Switzerland

So far four randomized studies, three of them double-blind and placebo-controlled, have investigated the role of bismuth subsalicylate (BSS) in the treatment of travelers' diarrhea. When compared with placebo BSS significantly reduced the number of unformed stools and increased the proportion of patients free of symptoms at the end of the trial. In the two studies that compared BSS with loperamide, the latter agent brought significantly faster relief. Diarrhea accompanied by dysenteric symptoms was influenced most favorably by administration of systemic antimicrobial agents. In all four studies only minor adverse effects were noted with BSS or the other active agents. One may include loperamide and a systemic antimicrobial agent in one's travel kit; however, loperamide should not be used for dysentery, and the antimicrobial agent should not be used in uncomplicated cases. As an alternative, although it is less effective, BSS has the unique advantage of being safe enough to use for all patients with travelers' diarrhea.

Each year 16 million persons who travel from an industrialized country to a developing country are at considerable risk of developing travelers' diarrhea $[1,2]$. These travelers have been discouraged from taking any prophylactic medication [3], and experience shows that they are usually unable or unwilling to maintain perfect vigilance with respect to eating or drinking habits [4]. Instead of observing the traditional rule - "boil it, cook it, peel it, or forget it" - travelers want to enjoy their freedom, in the manner of Mark Twain, who once remarked, "Part of the secret of success is to eat what you like and let the food fight it out inside." Self-treatment of travelers' diarrhea, therefore, remains an important issue.

This report summarizes the four clinical trials that have so far been carried out on the role of bismuth subsalicylate (BSS) in (self-)treatment of travelers' diarrhea.

\section{Subjects and Methods}

The first trial (trial 1) was conducted by DuPont et al. [5]. Students originating from the United States and in Latin America were studied between June 1975 and April 1976 while they were attending a university in Cholula, Mexico (figure 1). Unless they

Please address requests for reprints to Dr. Robert Steffen, Institute of Social and Preventive Medicine, Sumatrastrasse 30, CH-8006 Zurich, Switzerland. were already taking antidiarrheal or antimicrobial agents, students with three or more unformed stools in the preceding 24 hours associated with one or several symptoms of enteric infection were treated with BSS or placebo (table 1) in this randomized doubleblind trial. Patients with more severe illness (as reflected by five or more unformed stools per 24 hours) were given a double dose. In both treatment groups, medication was taken for only $31 / 2$ hours. All students collected stool samples, which were analyzed in a field laboratory.

In the second study (trial 2), again conducted by the Houston group [6], adult students were recruited from volunteers working in seven Latin American countries and from students from the United States and Latin America who were attending courses in Guadalajara, Mexico. Diarrhea, in this study, was defined as four or more unformed stools associated with one or more symptoms of enteric infection. Exclusion criteria similar to those in trial 1 applied, but, additionally, all subjects with dysentery or a temperature of $>102^{\circ} \mathrm{F}$ were excluded. In this non-blind, randomized study, the subjects received either BSS or loperamide for 2 days (table 1). Each subject kept a daily record of symptoms and medication. Stools were sent either to Houston or to the field laboratory in Guadalajara in three-vial fecal transport systems.

The third study (trial 3) was a joint study by the Houston group in Mexico and the Zurich group in Banjul, The Gambia [7]. It was undertaken to com- 
Figure 1. Location of four trials of the therapeutic efficacy of BSS in travelers' diarrhea.

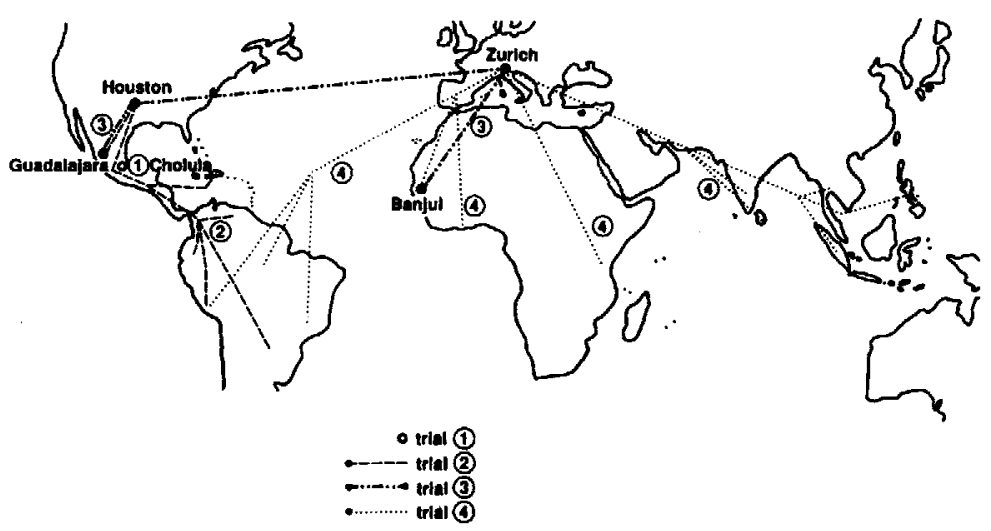

pare etiologic agents in two widely different locations, to test two preservation kits for transportation of stool specimens from West Africa to Houston, and to evaluate BSS with the use of various disease-severity criteria for entrance into the study (table 1). We will concentrate here on the latter aspect. A dose of $4.2 \mathrm{~g}$ of BSS or placebo was given to the volunteers in a double-blind, randomized manner. Whereas patients in Mexico were included in the study only after they had voided at least three unformed stools, those in West Africa could start treatment immediately, conditions that mimick the actual pattern of usage.

For the fourth study (trial 4), visitors to the Zurich University Vaccination Center were invited to participate on a voluntary basis in a study of self-

Table 1. Entrance criteria and regimens used in four trials of self-treatment of travelers' diarrhea.

\begin{tabular}{|c|c|c|c|}
\hline Study, entrance criteria & Agent, dosage & $\begin{array}{l}\text { Dosage over } \\
24 \mathrm{~h}\end{array}$ & $\begin{array}{c}\text { No. of } \\
\text { participants }\end{array}$ \\
\hline \multicolumn{4}{|l|}{ Trial 1} \\
\hline \multirow[t]{2}{*}{$\geqslant 3$ unformed stools $/ 24 \mathrm{~h}$} & BSS, $525 \mathrm{mg}$ in 8 half-hourly doses & $4.3 \mathrm{~g}$ & 56 \\
\hline & Placebo, same & $\ldots$ & 55 \\
\hline \multirow[t]{2}{*}{$\geqslant 5$ unformed stools $/ 24 \mathrm{~h}$} & BSS, $1,050 \mathrm{mg}$ in 8 half-hourly doses & $8.4 \mathrm{~g}$ & 27 \\
\hline & Placebo, same & $\ldots$ & 31 \\
\hline \multicolumn{4}{|l|}{ Trial 2} \\
\hline \multirow{2}{*}{$\begin{array}{l}\geqslant 4 \text { unformed stools } / 24 \mathrm{~h} \text {, plus } \\
\text { other symptom(s) }\end{array}$} & BSS, $525 \mathrm{mg}$ in 8 half-hourly doses & $3.1-4.2 \mathrm{~g}$ & 107 \\
\hline & $\begin{array}{l}\text { Loperamide, initial dose } 4 \mathrm{mg} \text {, then } 2 \mathrm{mg} \text { after } \\
\text { each unformed stool ( } \leqslant 8 \mathrm{doses} / 24 \mathrm{~h} \text { ) }\end{array}$ & $4-16 \mathrm{mg}$ & 111 \\
\hline \multicolumn{4}{|l|}{ Trial 3 (West Africa) } \\
\hline \multirow[t]{2}{*}{ Onset of symptoms } & BSS, $1,050 \mathrm{mg}$ in 4 hourly doses & $4.2 \mathrm{~g}$ & 67 \\
\hline & Placebo, same & & 63 \\
\hline \multicolumn{4}{|l|}{ Trial 3 (Mexico) } \\
\hline \multirow{2}{*}{$\begin{array}{l}\geqslant 3 \text { unformed stools in an } 8 \text {-hour } \\
\text { period or } \geqslant 4 \text { in } 24 \mathrm{~h} \text {, plus } \\
\text { other symptoms }\end{array}$} & BSS, $525 \mathrm{mg}$ in 8 half-hourly doses & $4.2 \mathrm{~g}$ & 49 \\
\hline & Placebo, same & $\cdots$ & 50 \\
\hline \multicolumn{4}{|l|}{ Trial $4 *$} \\
\hline \multirow[t]{7}{*}{ Onset of symptoms } & BSS, $525 \mathrm{mg}$ in 8 half-hourly doses & $4.2 \mathrm{~g}$ & 400 \\
\hline & Doxycycline, $100 \mathrm{mg}$ twice daily & $200 \mathrm{mg}$ & 400 \\
\hline & $\begin{array}{l}\text { Loperamide, initial dose } 4 \mathrm{mg} \text {, then } 2 \mathrm{mg} \text { after } \\
\text { each unformed stool }(\leqslant 8 \text { doses } / 24 \mathrm{~h} \text { ) }\end{array}$ & $4-16 \mathrm{mg}$ & 400 \\
\hline & Mecillinam, $400 \mathrm{mg}$ three times daily & $1.2 \mathrm{~g}$ & 400 \\
\hline & Streptococcus faecium, $75 \times 10^{6} \mathrm{SF} 68$ & $225 \times 10^{6} \mathrm{SF} 68$ & 400 \\
\hline & TMP-SMZ, $160 / 800 \mathrm{mg}$ twice daily & $320-1,600 \mathrm{mg}$ & 150 \\
\hline & Placebo, various dosing periods & $\ldots$ & 430 \\
\hline
\end{tabular}

* Not all of the participants in trial 4 had diarrhea. 
treatment of travelers' diarrhea if they were going to travel to Africa, Asia, or Latin America for 7-31 days and were 16-70 years of age [8].

The six active agents listed in table 1 and identicallooking placebos for each were assessed. Medication was distributed in a double-blind manner on the basis of order of appearance of the name of the volunteers in computer-generated randomization lists, and distribution was stratified for the continent visited. The volunteers received verbal and written instructions to the effect that they were not to take any medication so long as they had no diarrhea, but they could start self-treatment immediately after onset of symptoms. Diarrhea was defined as at least one watery stool or a pasty stool when accompanied by concomitant symptoms, such as cramps, nausea, vomiting, or fever. Unformed stools were defined as a combination of watery and pasty stools. By allowing treatment immediately upon onset of symptoms, we again wanted to imitate the actual usage pattern. Once initiated, self-treatment was to be continued for $\mathbf{4 8}$ hours, or at least until the symptoms vanished. If no improvement was observed after this time, the volunteers were advised to see a local doctor.

Upon return, the volunteers were to immediately send back a completed questionnaire and the remaining test medication. Compliance was judged on the basis of the questionnaire and on the pill count. Efficacy and adverse effects were evaluated according to the questionnaire. Cure was defined as the disappearance of all symptoms. No stool samples were analyzed.

\section{Results}

Trial 1 showed a significant decrease in stool frequency in both the low-dose and the high-dose BSS groups when compared with the placebo group for the 4- to 24-hour surveillance period (figure 2). During the second day, a level of significance was reached only in the students who received the higher dose of the active drug. One wonders whether the higher dose of BSS offered faster relief; but, astonishingly, upon initiation of therapy, the patients who received placebo in the groups with severe illness also voided fewer unformed stools than did their counterparts in the moderately ill group.

BSS was similarly effective in the treatment of travelers' diarrhea of various etiologic origin. Eight students with shigellosis received $8.4 \mathrm{~g}$ of BSS daily, while all other students in this separate analysis were

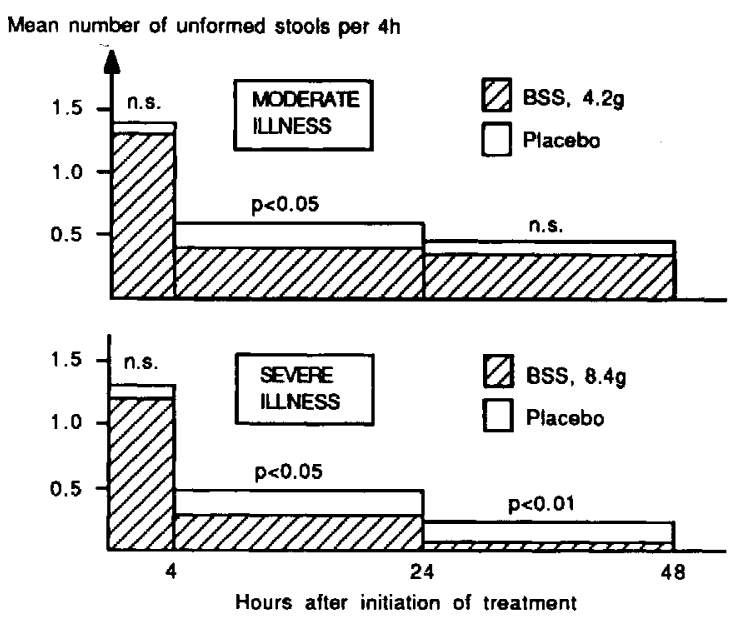

Figure 2. Mean number of unformed stools after BSS or placebo therapy in trial 1 ; n.s. = not significant.

given only $4.2 \mathrm{~g}$ daily. A significance level of $P<.05$ was reached only in the group with diarrhea due to enterotoxigenic Escherichia coli (ETEC) for the 4to 24-hour and 4- to 48-hour periods. In the other etiologic groups the trend was less pronounced but was favorable for BSS as well. Patients with shigellosis in the active treatment groups did not experience a prolonged illness. Subjective relief of the symptoms of diarrhea, nausea, and abdominal pain within 24 hours of therapy was reported significantly more often in the BSS group.

According to results from trial 2, loperamide reduced the number of unformed stools faster than did BSS (figure 3). This benefit was most marked during the first hours and the first day of illness. Subjects whose condition did not improve with the test medication could choose to take trimethoprimsulfamethoxazole (TMP-SMZ); 25\% in each treatment group elected to do so. Analysis of the response to therapy by etiologic agents showed that loperamide reduced the number of unformed stools faster for all etiologic categories during all assessed time intervals. However, again, the significance level was reached only within the first day.

In trial 3 the enteropathogens isolated were very similar at both study sites (table 2), especially if we consider that in West Africa two different vial kits were used, which explains the higher rates of isolation.

Compared with placebo, BSS in both West Africa and Mexico reduced by $25 \%$ the time from initiation of therapy to the last unformed stools and re- 
Figure 3. Median number of unformed stools after BSS or loperamide therapy in trial 2 .
Median number of unformed stools per $4 \mathrm{~h}$

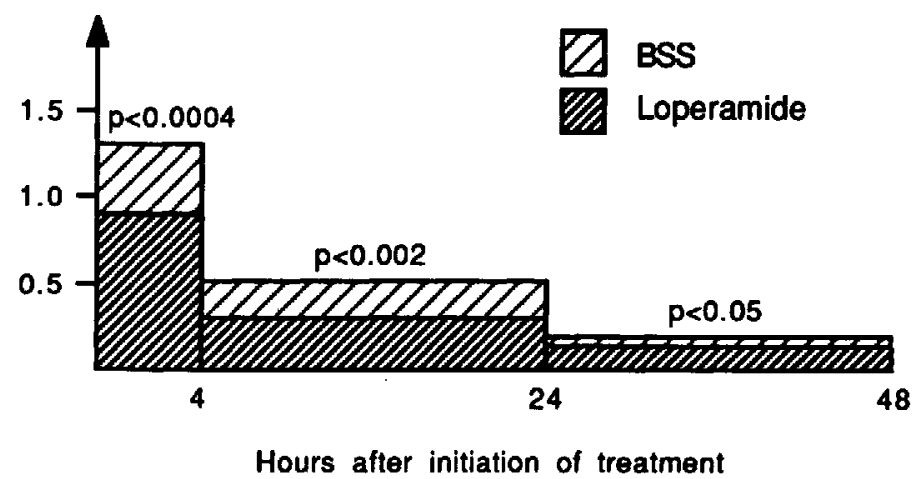

duced by $\sim 20 \%$ the time until total relief from all symptoms $(P<.02)$. Figure 4 illustrates that the decrease in unformed stools passed was similar to that in the other studies. At the end of the observation period, diarrhea persisted significantly more often in the placebo group. BSS relieved severe illness as effectively as it relieved mild illness.

In trial $4,38 \%$ of the study population of 2,098 (2,580 recruits; 482 drop-outs) suffered from diarrhea but only $654(31 \%)$ took their trial medication. Of those who took their medication, $\sim 10 \%$ in each of the self-treatment groups showed poor compliance $(n=63)$ and had to be excluded on the basis of either recorded intake of medication or the pill count; $\mathbf{3 5}$ of the volunteers took another medication

Table 2. Enteropathogens identified in pretreatment stool specimens.

\begin{tabular}{lcc}
\hline & $\begin{array}{c}\text { Percentage of specimens } \\
\text { from indicated area } \\
\text { with pathogen }\end{array}$ \\
\cline { 2 - 3 } Pathogen & West Africa & Mexico \\
\hline ETEC & 42 & 24 \\
EAEC & 7 & 6 \\
EIEC & 0 & 2 \\
Shigella species & 7 & 6 \\
Salmonella species & 4 & 1 \\
Campylobacter jejuni & 1 & 2 \\
Cryptosporidium & 2 & 0 \\
Aeromonas & 0 & 1 \\
Pseudomonas shigelloides & 7 & 0 \\
Entamoeba histolytica & 2 & 0 \\
Giardia lamblia & 0 & 2 \\
\hline
\end{tabular}

NOTE. Among participants in West Africa, pathogens were isolated in $79(60 \%)$ of 132 specimens; in Mexico, 42 (38\%) of 112 specimens. $\mathrm{ETEC}=$ enterotoxigenic $E$. coli $; \mathrm{EAEC}=$ enteroadherent $E$. coli , EIEC $=$ enteroinvasive $E$. coli. during the trial period; an additional 17 were excluded because they gave contradictory answers; and nine were withdrawn from efficacy evaluation because they had adverse reactions and discontinued medication. Thus, 530 volunteers were evaluated for drug efficacy.

The travelers who were evaluated showed no significant differences with respect to age, sex, destination, or travel style. Since the travelers were allowed

Median number of unformed stools
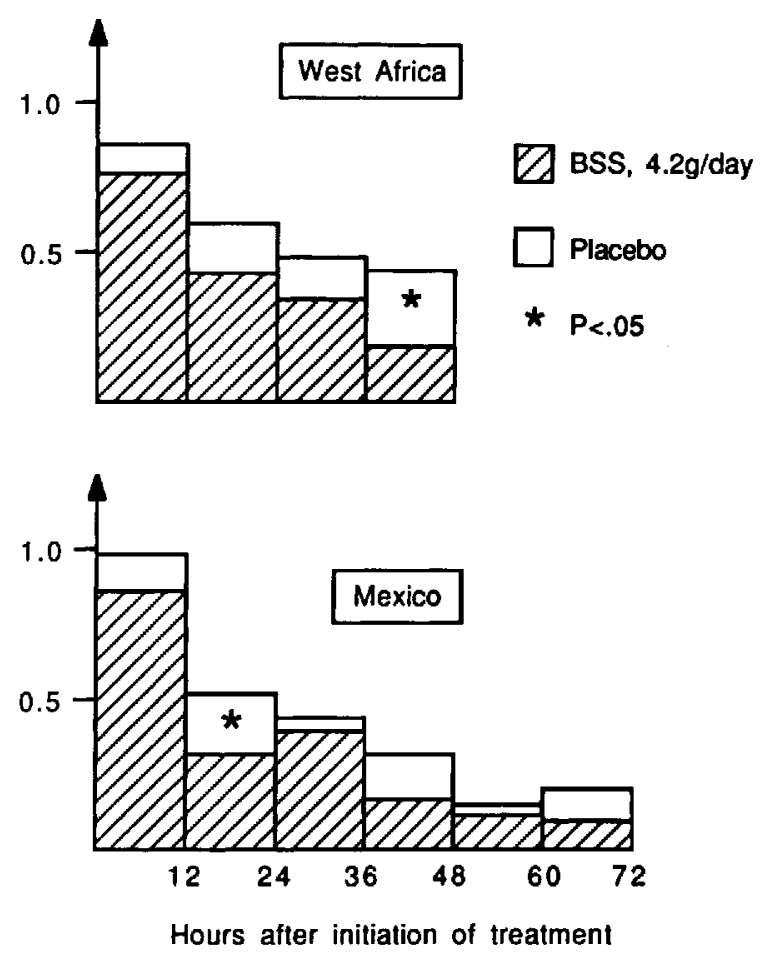

Figure 4. Median number of unformed stools after BSS or placebo therapy in trial 3. 


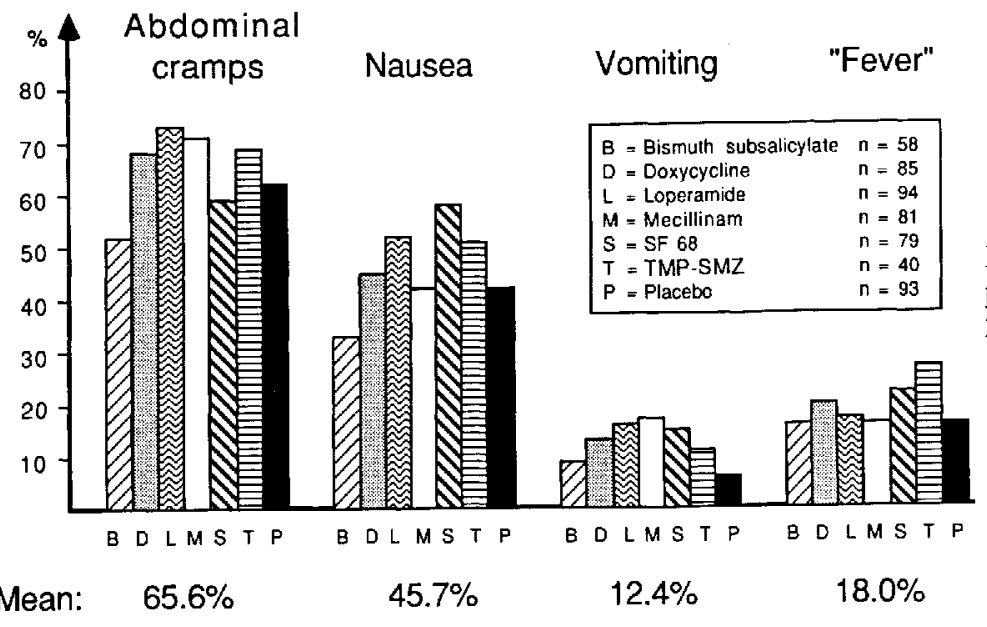

Figure 5. Concomitant symptoms in patients with diarrhea during the first 24 hours of treatment.

to start treatment immediately, it remains unknown whether the participants in all treatment groups were suffering from diarrhea of similar severity. However, when the incidence of concomitant symptoms was compared among the various treatment groups, no significant differences were detected. The lower proportion of symptoms in the BSS group (figure 5) may be explained by less severe disease, or BSS may have prevented these symptoms more effectively than other active agents during the first $\mathbf{2 4}$ hours of treatment. These lower proportions just missed significance according to the $\chi^{2}$ test, which was applied throughout the study.

The assessment of the time from initial medication until disappearance of symptoms showed significant differences between the various agents tested: slightly more than $40 \%$ of those who took loperamide were cured within 4 hours, making this agent clearly the fastest-acting one (figure 6). After 8 and 24 hours, this lead was reduced, with BSS and TMP-SMZ showing similar success rates. After 48 hours all active agents (except for SF 68, which never showed any significant benefit) had cured $\sim 80 \%$ of all patients. Similar success and failure rates were observed in East and West Africa, Asia, and Latin America.

Approximately $20 \%$ of all patients remained sick in each treatment group after 48 hours. Future studies will have to determine the causes of the delay in cure and the outcome in these patients.

The number of unformed stools possibly decreased most in the loperamide group during the first 24 hours of treatment (figure 7). However, as men- tioned above, the patients were allowed to start treatment immediately, and we are unable to ascertain whether diarrhea was of the same severity in the various treatment groups. During the second day of treatment, the patients in all treatment groups except the SF 68 group had an average of 1.4-1.7 bowel movements.

Patients with dysentery, defined here as the presence of fever and/or blood mixed with stools, showed results different from those in patients with nondysenteric illness. All agents except for placebo and SF 68 were effective in $80 \%-90 \%$ of the nondysen-

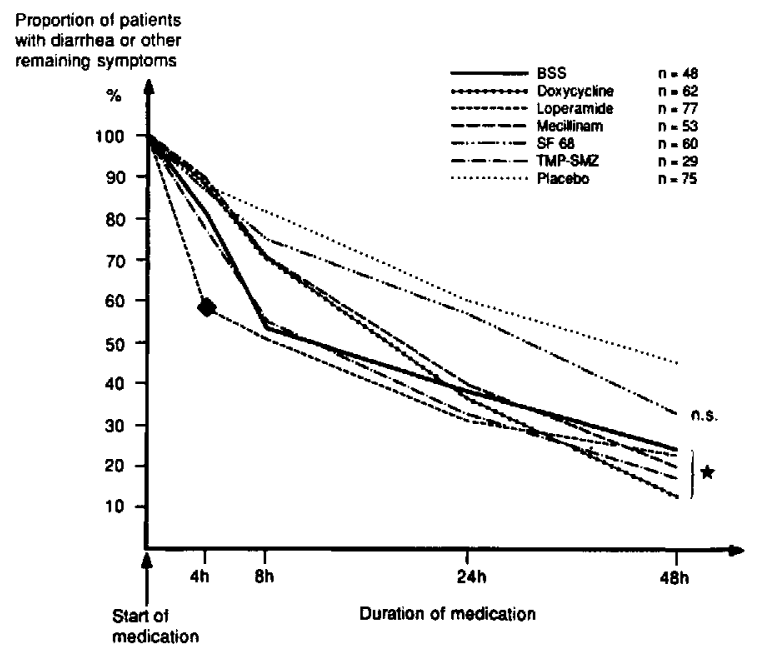

Figure 6. Proportion of patients cured by various therapeutic agents within defined time periods in trial $4 ;(\bullet)=$ $P<.0001$ compared with other agents, $(\star)=P<.006$ for any agent compared with placebo. 


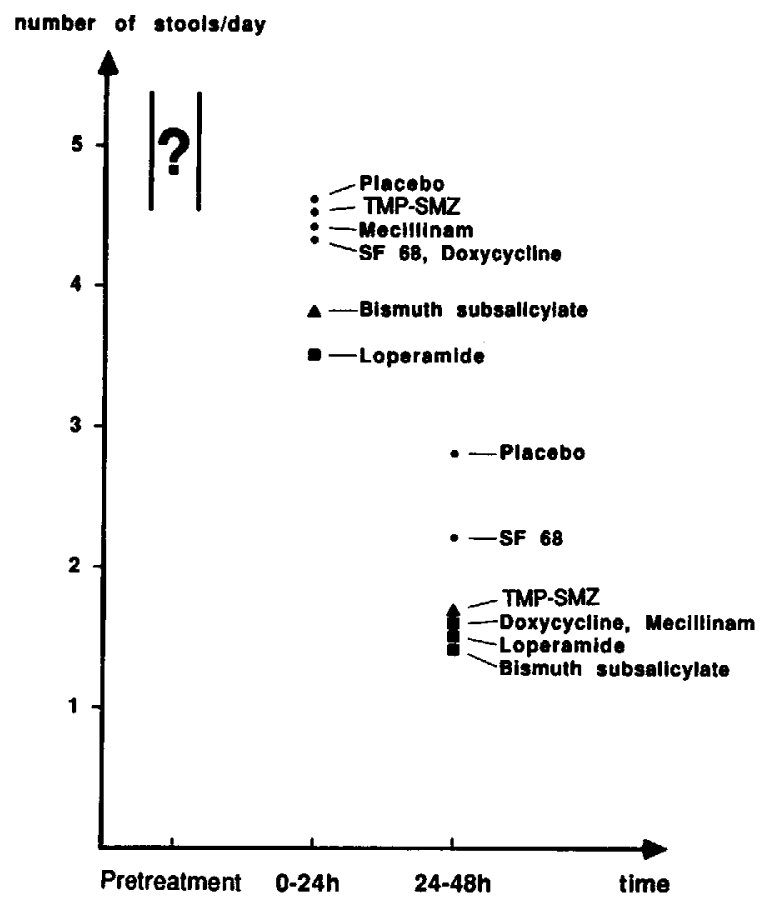

Figure 7. Average number of unformed (watery or pasty) stools in different treatment groups during various treatment periods as compared with that in placebo group (trial 4).

teric cases. In patients with dysenteric symptoms, which accounted for $18 \%$ of all diarrheas, only antimicrobial agents showed similar rates. In view of the small number of dysenteric cases, no significant differences in outcome could be detected. Loperamide may be less effective than systemic antimi-

Table 3. Concomitant symptoms alleviated by therapy as compared with placebo.

\begin{tabular}{|c|c|c|c|c|c|}
\hline \multirow[b]{3}{*}{ Therapy } & \multicolumn{5}{|c|}{$\begin{array}{l}\text { Percentage of patients whose concomitant } \\
\text { symptoms were alleviated at indicated time }\end{array}$} \\
\hline & \multicolumn{2}{|c|}{ Abdominal cramps } & \multirow{2}{*}{$\begin{array}{c}\text { Nausea } \\
48 \mathrm{~h}\end{array}$} & \multirow{2}{*}{$\begin{array}{c}\text { Vomiting } \\
48 \mathrm{~h}\end{array}$} & \multirow{2}{*}{$\begin{array}{c}\text { “Fever" } \\
48 \mathrm{~h}\end{array}$} \\
\hline & $24 \mathrm{~h}$ & $48 \mathrm{~h}$ & & & \\
\hline BSS & $51.4^{*}$ & 62.1 & 62.5 & 33.3 & 44.4 \\
\hline Doxycycline & $57.1^{\dagger}$ & $81.0^{\ddagger}$ & $80.6^{*}$ & 77.8 & 75.0 \\
\hline Loperamide & $67.6^{\ddagger}$ & $77.9 \ddagger$ & 72.3 & 71.4 & 53.3 \\
\hline Mecillinam & $66.7 \ddagger$ & $81.4 \ddagger$ & $81.8 *$ & 83.3 & 69.2 \\
\hline SF 68 & 48.0 & $67.4^{*}$ & 66.7 & 80.0 & 68.8 \\
\hline TMP-SMZ & $67.7^{\dagger}$ & $77.8^{*}$ & 80.0 & 50.0 & 77.8 \\
\hline Placebo & 31.1 & 45.6 & 51.2 & 33.3 & 43.8 \\
\hline
\end{tabular}

$* P<.05$.

$\dagger P<.01$.

$\mp P<.001$ crobial agents, but it showed no tendency to increase the proportion of participants with persistent dysenteric disease when compared with the proportion in the placebo group. However, a longer follow-up would be needed to judge this.

Analysis of the cure rate of the symptoms concomitant with diarrhea showed no significant differences with respect to vomiting or fever between participants given active agents and those given placebo. On the other hand, a systemic antimicrobial agent and loperamide were superior in curing abdominal cramps.

No serious adverse reactions occurred in any of the four studies with any of the active agents. Black tongue and black stools were reported, but these are anticipated effects of BSS therapy. Tinnitus, constipation, and other symptoms were not significantly increased in any treatment group of any study described.

\section{Discussion and Conclusions}

In all trials BSS was significantly superior to placebo in several respects. It decreased stool frequency in the total study population and in subsegments of specific etiology, including shigellosis. It increased the proportion of patients relieved of symptoms within the study period and reduced the time until total relief. According to both studies in which BSS was compared with loperamide, the latter exerted a faster effect than BSS.

Taking four or eight doses of BSS within 4 hours after initiation of treatment is not convenient if treatment is begun late in the evening. Spacing out the frequency of administration might lead to more convenience as well as to greater efficacy, as in the prevention studies. As reported by Gryboski [9], a therapeutic regimen of BSS every 3 hours has been successfully tested in a pediatric population, but such a regimen (or possibly a standard dosing of four times daily) needs to be confirmed in adult patients with travelers' diarrhea.

The toxicity of the agents described in this review and those used in self-therapy for travelers' diarrhea seems to be more a theoretical concern than of practical relevance. Although hundreds of volunteers included in our various studies were invited to call us collect from any place in the world in case of severe adverse reactions, none ever did so, and no severe adverse event was reported in the questionnaires. Apparently, other researchers in this field have had simi- 
lar experiences. If the dosage and duration of treatment as prescribed by the manufacturer is not exceeded, BSS seems to be a safe agent [10]. Similarly, loperamide is well tolerated, but two studies indicated that in dysenteric cases illness may be slightly aggravated $[11,12]$. There is no indication at all that this may be the case in nondysenteric travelers' diarrhea, and to our knowledge no severe adverse reactions have been reported in treatment of such cases with loperamide. Systemic antimicrobial agents above all have a known, significant incidence of allergic reactions.

As shown by the most recent study (trial 4), diarrhea continues to bother more than one-third of travelers to the tropics. Apparently, the etiology of travelers' diarrhea is similar everywhere [13, 14]; consequently, the same therapeutic regimen would apply everywhere.

When considering what to add to a travel kit for treatment of travelers' diarrhea, or for self-therapy after return home, the first choice is loperamide for the more common nondysenteric diarrhea and systemic antimicrobial agents for dysenteric cases. Although it is less rapidly effective, BSS may be a second choice that also has one definite advantage: it is the agent that adults can take at the prescribed eight dosages of $525 \mathrm{mg}$ of BSS every half hour to one hour for all types of travelers' diarrhea. Since 16 tablets of $262.5 \mathrm{mg}$ or almost a quarter liter of the liquid preparation will be needed every 24 hours, a significant addition to the volume of luggage must be considered if the traveler chooses to take BSS.

\section{References}

1. Steffen R, Van der Linde F, Gyr K, Schar M. Epidemiology of diarrhea in travelers. JAMA 1983;249:1176-80

2. Steffen R, Boppart I. Travelers' diarrhoea. Bailliere's Clinical Gastroenterology 1987;1:361-75

3. Consensus Conference. Travelers' diarrhea. JAMA 1987;253: 2700-4

4. Kozicki M, Steffen R, Schär M. "Boil it, cook it, peel it or forget it": does this rule prevent travelers' diarrhoea? Int J Epidemiol 1985;14:169-71

5. DuPont HL, Sullivan P, Pickering LK, Haynes G, Ackerman PB. Symptomatic treatment of diarrhea with bismuth subsalicylate among students attending a Mexican university. Gastroenterology 1977;73:715-8

6. Johnson PC, Ericsson CD, DuPont HL, Morgan DR, Bitsura JAM, Wood LV. Comparison of loperamide with bismuth subsalicylate for the treatment of acute travelers' diarrhea. JAMA 1988;255:757-60

7. Steffen R, Mathewson JJ, Ericsson CD, DuPont HL, Helminger A, Balm TK, Wolff K, Witassek F. Travelers' diarrhea in West Africa and in Mexico: fecal transport systems and liquid bismuth subsalicylate for self therapy. $\mathrm{J}$ Infect Dis 1988;57:1008-13

8. Steffen R, Heusser R, Tschopp A, DuPont HL. Efficacy and side-effects of six agents in the self-treatment of travelers' diarrhoea. Travel Medicine International 1988;6:153-7

9. Gryboski JD, Kocoshis S. Effect of bismuth subsalicylate on chronic diarrhea in childhood: a preliminary report. Rev Infect Dis 1990;12(Suppl 1):S36-40

10. Steffen R, Heusser R, DuPont HL. Prevention of travelers' diarrhea by nonantibiotic drugs. Rev Infect Dis 1986; 8(Suppl 2):S151-9

11. DuPont HL, Hornick RB. Adverse effect of lomotil therapy in shigellosis. JAMA 1973;226:1525-8

12. Steffen R, Stansky M, Kozicki M. Vorbeugende Massnahmen gegen Reisediarrhöe. Schweiz Med Wochenschr 1984; 114(Suppl 17):35-8

13. Black RE. Pathogens that cause travelers' diarrhea in Latin America and Africa. Rev Infect Dis 1986;8(Suppl 2): S131-5

14. Taylor DN, Echeverria P. Etiology and epidemiology of travelers' diarrhea in Asia. Rev Infect Dis 1986;8(Suppl 2):S136-41 